\title{
A INTERNALIZAÇÃO DA EXCLUSÃO
}

\author{
Luiz Carlos de Freitas*
}

RESUMO: Procura-se mostrar as formas dissimuladas que as políticas públicas neoliberais colocaram em funcionamento com a finalidade de reduzir custos econômicos, sociais e políticos das formas de exclusão objetivas (repetência e evasão), sem alterar em essência a seletividade da escola, criando um campo de exclusão subjetiva (auto-exclusão, exclusão entre ciclos, "trilhas de progressão continuada diferenciadas"), no qual a responsabilidade da exclusão recai sobre o próprio excluído. São apresentadas três teses na tentativa de compreender este movimento. A primeira trata da conversão da exclusão objetiva em exclusão subjetiva; a segunda mostra como os mecanismos da avaliação informal são acionados no sentido de criar "trilhas de progressão continuada diferenciadas" nas propostas de organização por ciclos de progressão continuada; e, finalmente, a terceira aponta a desresponsabilização da escola em relação à escolarização das camadas populares ("aprender a aprender"), na esteira da desresponsabilização do próprio Estado mínimo proposto pelas atuais políticas públicas. Finalmente, apresentam-se por contraste elementos para uma política alternativa voltada para as responsabilidades formativas da escola que visem a transformar a relação entre as pessoas e entre estas e a natureza.

Palavras-chave: Políticas públicas. Exclusão subjetiva. Avaliação informal. Progressão continuada. Desresponsabilização.

\section{THE INTERNALIZATION OF EXCLUSION}

ABSTRACT: This paper aims at showing the concealed forms that the neoliberal public policies implemented in order to reduce the economical, social and political costs of the objective forms of exclusion (repetition and desertion). Without modifying the essence of school selectivity, they created a field of subjective exclusion (auto-exclusion, exclusion between cycles, "trilhas de progressão continuada differenciadas"), in which the very person excluded is

Professor da Faculdade de Educação da Universidade Estadual de Campinas (UniCAmp).

E-mail: freitas.lc@uol.com.br

Educ. Soc., Campinas, v. 23, n. 80, setembro/2002, p. 299-325

Disponível em <http://www.cedes.unicamp.br> 
responsible for their exclusion. Three theses are presented in an attempt to understand this movement. The first one deals with the conversion of the objective exclusion into subjective exclusion. The second one shows how the mechanisms of informal assessment function to create "trilhas de progressão continuada diferenciadas" in the organization proposals by cycles of continued progression. Finally, the last one pinpoints the "deresponsibilization" of school with regards to the schooling of the lower classes ("learn to learn"), in the wake of the "deresponsibilization" of the very minimal State proposed by the current public policies. Finally, by contrast, the author presents some elements for an alternative policy directed to the training responsibility of school; elements aimed at transforming the relationship among people and between them and nature.

Key words: Public policies. Subjective exclusion. Informal assessment. Continued progression. "Deresponsibilization".

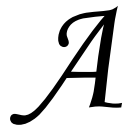

os poucos as falácias do neoliberalismo e da globalização vão sendo desveladas. ${ }^{1}$ As teorias que deram sustentação, especialmente nesta última década no campo da educação, a toda esta re-acomodação do padrão de exploração dos trabalhadores e do próprio padrão de acumulação de riqueza, terão, também, o mesmo destino. Mas não nos iludamos quanto ao poder de renovação dessas "teorias" e se suas variadas formas de dissimulação.

O discurso pedagógico atual começa a ficar mais nítido na apreciação dos resultados das políticas públicas neoliberais, resultados estes que já não podem ser facilmente ocultados e que mostram a que vieram (desemprego estrutural, desindustrialização, dependência de impérios financeiros externos, generalização da violência endêmica, exclusão social, fraudes financeiras e contábeis como forma de acumulação, intensificação da exploração do trabalhador etc.). Está chegando o momento em que tais políticas serão avaliadas e confrontadas com as suas conseqüências - elas, seus proponentes e seus apoiadores.

Particularmente, do ponto de vista da teoria da educação, acho que a década de 1990 não foi uma década perdida e vai nos ensinar muito. Entre seus ensinamentos, certamente, estará o de que não é possível querer "fazer justiça com as próprias mãos" e "tornar o sistema educacional um sistema justo" em meio a uma sociedade que aprofunda a injustiça do lado de fora da escola, mantém antigas e cria novas formas de exclusão dentro e fora da escola, e cuja determinação fundamental não foi alterada nos últimos 400 anos $^{2}$ - ou seja: a exploração do homem pelo homem. O canto da sereia sobre a 
“eqüidade” começa a desafinar. Alguns irão se dar conta, penosamente, de como foram habilmente envolvidos em um processo de legitimação de estratégias de regulação em um Estado cuja função é sustentar, rearticular e apoiar a modernização e intensificação das formas de exploração ${ }^{3}$ - a próxima fase da educação, portanto, poderá ser de "pessimismo pedagógico" em contraposição ao "otimismo pedagógico" de alguns em nossos dias. E para os que se refugiaram nas belas "teorias das brechas", recheadas de falta de referência como forma de sublimar contradições reais e criar a sensação de que "fizeram algo de concreto pela educação", de que "superaram o denuncismo, todos juntos de mãos dadas pela educação", temos uma péssima notícia - o mundo aqui embaixo continua feio... Fraternamente, aguardamos o retorno destes para ampliar a luta. A batalha pela educação e pela eqüidade não é uma tarefa do tipo "one man, one show" e não pode ser conseqüentemente travada sem o apoio de amplos movimentos sociais emancipatórios que questionem radicalmente as bases das relações de exploração vigentes. Talvez esta seja a maior reaprendizagem para os educadores, neste início de século. No entanto, as possibilidades continuam presentes aguardando mais combatentes.

Para o senhor ministro da Educação:

O país conseguiu antecipar e superar a meta estabelecida pelo Plano Decenal de Educação para Todos, que previa elevar para, no mínimo, 94\% a cobertura da população em idade escolar, até 2003. Estamos com $97 \%$ das crianças na escola. A década de 90 foi um marco. A discussão sobre a educação está hoje centrada na qualidade, o que é um importante avanço. (Souza, 2001)

Para nós, a questão do acesso sempre esteve associada à questão da qualidade. Há décadas que os educadores lutam, simultaneamente, por acesso a uma educação de qualidade. De fato, a questão do acesso perde sentido sem a questão da qualidade. Não são dois momentos, mas sim um único e mesmo movimento. Sua divisão em duas etapas obedece às mesmas razóes pelas quais, no passado, pediram-nos que esperássemos pelo crescimento do "bolo" antes de reparti-lo.

Somente na década de 1990, quando a ausência de uma "determinada qualidade" começou a incomodar as perspectivas de crescimento das taxas de acumulação de riquezas - não somente como preparação para o trabalho, mas como forma de reduzir custos 
sociais e como forma de ampliação do controle político-ideológico (ainda que pela simples guarda das crianças nos aparatos escolares, já que a escola não ensina apenas pelo seu conteúdo escolar) -, a questão da "qualidade" foi pautada pelos empresários e, conseqüentemente, pelos governos. A noção de qualidade a que se refere o ministro está restrita à medição de habilidades desgarradas da qualidade de vida, presa na lógica do custo/benefício. Em seu artigo, linhas após, a própria realidade (o fracasso brasileiro no exame do PISA $)^{4}$ encarrega-se de fazê-lo dizer que esse fracasso foi compreensível pois a "escola não opera no vácuo". Portanto, a real qualidade da escola fica limitada pela qualidade de vida.

As dificuldades para a melhoria da qualidade na escola advêm da própria concepção de escola que se tem e de como se concebe a possibilidade de aumentar essa qualidade atualmente: por adição de controle sobre a escola (especialistas supervisionando professores, controle do currículo, avaliação interna e externa) e por adição de tecnologia (treinamento, equipamentos, infra-estrutura etc.). Esta é a forma mais "avançada" pela qual o capitalismo consegue imaginar a "escola de qualidade". Ela é herdeira de como ele vê a melhoria nas outras instituições sociais, em especial nas empresas - troca da base tecnológica e da forma de gestão da força de trabalho. O exemplo do estado do Ceará ilustra esta visão:

No lugar de um professor para cada disciplina, o telensino trabalha com somente um profissional, chamado de orientador de aprendizagem, que monitora e debate com os alunos os temas relacionados às oito disciplinas do Ensino Fundamental. Apenas recentemente, em 1999, o governo aumentou o número de orientadores para três por classe. (Grifos meus)

Lindalva, no governo há oito anos, acredita que o telensino não é o culpado pela eventual falta de qualidade da Educação do Ceará. "Não é o telensino que está mal. A Educação brasileira está mal”, argumenta a subsecretária. Ela garante que as aulas transmitidas pela TV são modernas, os livros atualizados e que as bibliotecas escolares fornecem material suficiente para os professores aprofundarem os conteúdos. "Se o profissional não vai atrás, é decisão dele", afirma. (Grifos meus)

A reportagem de Nova Escola On-Line visitou seis escolas estaduais cearenses em cinco municípios diferentes. Todos os professores ouvidos - cerca de 30 profissionais - fizeram críticas ao telensino, alegando que as aulas são muito rápidas. Eles também reclamam que não podem fazer revisões, pois as aulas são transmitidas em canal aberto. Uma professora de um colégio estadual de Fortaleza, que não quis se identificar, afirmou que toda a teoria envolvida nos conceitos de "sujeito e predicado" é vista em um vídeo de 6 minutos. (Grifos meus) 
A queixa mais comum entre os professores entrevistados, no entanto, é a polivalência exigida pelo telensino. Para Samia Ponte, professora da oitava série do Colégio Estadual José Euclides Ferreira, unidade localizada em Sobral e que leva o nome do pai do ex-governador do Ceará, Ciro Gomes, não é possível acompanhar todos os conteúdos transmitidos pela TV. Formada apenas em Letras, ela leciona Matemática, História, Religiāo e Ciências, além de Lingua Portuguesa. Samia, que garante se esforçar muito para dar aulas interessantes aos alunos, assume que não consegue responder todas as dúvidas. "Vou mentir?", pergunta ela. "Com uma capacitação formal tenho certeza de que me desempenharia melhor", afirma. (Grifos meus)

A situação de Socorro Medeiros, de 34 anos, é um exemplo de que o telensino pode realmente não estar funcionando. Ela completou o ensino fundamental no sistema, mas não se formou no ensino médio. "Não consegui acompanhar as aulas", conta. Hoje, Socorro é faxineira do Colégio Estadual Jenny Gomes, em Fortaleza. (Grifos meus) (Guimarães, 2002)

Outro exemplo pode ser o próprio estado de São Paulo, onde inovações foram verticalmente "implantadas". Vejamos alguns trechos do que os professores dizem, em São Paulo (região de Campinas), em uma pesquisa que fizemos dentro de um curso de especialização em avaliação (Freitas, 2000):

Há ainda o problema da aprovação, ou seja, progressão continuada que nos tem deixado angustiadas com certas situações de continuidade, porque alguns alunos vão para a série seguinte sem o mínimo de preparo e será que o próximo professor entenderá o trabalho iniciado? (Grifos meus)

Como tudo tem interesse político por trás, estamos cabreiros com essa progressão. Até que ponto estão realmente pensando nos alunos? Será que é uma maneira de manipular melhor a sociedade? Conversando com colegas professoras elas relatam que é para aprovar todo mundo e empurrar o ensino com a barriga. Que não vai existir mais notas e provas. Isso me deixa angustiada porque, até agora, não temos clareza dessa progressão e suas conseqüências, e o momento vai se tornando critico, perigoso. O que vai virar daqui um tempo? (Grifos meus)

Um aluno que não conseguiu o mesmo rendimento dos outros, por força do atual sistema, deve ir para a mesma turma que os que conseguiram um bom rendimento. Não acho isso errado, pelo contrário. O que não concordo é com as condiçôes que são oferecidas ao professor. (Grifos meus)

A única forma de enfrentar é falar sobre a avaliação e fazer resistência às normas da Secretaria da Educação. É trabalhar "nas brechas" que o sistema público oferece. (...) Não que seja fácil, pois na maior parte das vezes somos incompreendidos pelos próprios colegas, que procuram se agarrar a uma idéia de que a escola pública era melhor "antigamente" pois retinha-se quem não sabia. Mas não percebem que o contexto histórico era diferente e para essa 
escola, a política de exclusão dos alunos das classes pobres fazia seu papel, como a atual faz. (Grifos meus)

Progressão continuada é uma maquiagem. (Grifos meus)

$\mathrm{O}$ aluno está sendo empurrado como foi no $\mathrm{CB}$. A criança está sem aproveitar o que o sistema teoricamente diz. Faltam condições para isso. É lindo, mas não se consegue praticar. Estar na escola ou estar passando pela escola: o que vamos colocar como referência para avaliar a criança? (Grifos meus)

O que está acontecendo nos sistemas de ensino? Qual a lógica dessas modificações? Essas alteraçôes comportam várias análises. Selecionaremos aqui um dos ângulos possíveis.

Para compreendermos estes fatos, precisamos combinar dois conceitos que nos ajudarão neste processo. O primeiro deles é o conceito de "internalização de custos", no sentido de que o sistema escolar "toma consciência" dos custos econômicos da repetência e da evasão, para em seguida controlá-los e eventualmente "externalizá-los" por variadas formas de privatização. Este conceito deve ser combinado com outro, o da "exclusão branda", ou seja, a estratégia de criação de trilhas de progressão continuada diferenciadas no interior da própria escola, alterando o "metabolismo do sistema escolar" de forma a reforçar práticas de interiorização da exclusão. Se com o primeiro conceito se enfatiza a interiorização de custos econômicos, com o segundo enfatizam-se as práticas para controlar os custos sociais e políticos.

Vejamos o conceito de internalização de custos em Arrighi (1996):

As estratégias que estruturaram o ciclo holandês foram não apenas diferentes, mas, em aspectos fundamentais, opostas às estratégias que haviam estruturado o ciclo genovês anterior. As diferenças entre os dois ciclos são numerosas e complexas, mas todas podem ser referidas ao fato de que o regime de acumulação holandês, comparado e relacionado com o genovês, "internalizou os custos de proteção".

A idéia de "internalização dos custos de proteção" foi introduzida por Niels Steensgaard (1974) para explicar o espantoso sucesso, no século XVII, das companhias de comércio e navegação européias que operavam nas Índias Orientais. Sendo autônomas e competitivas no uso e no controle da violência, essas companhias "produziam" sua própria proteção, para usarmos a terminologia de Lane (1979, p. 22-28), a custos inferiores e mais fáceis de calcular do que os custos cobrados pelas autoridades locais às caravanas $\mathrm{e}$ navios. O que os comerciantes locais tinham que pagar em tributos, taxas e extorsōes, as companhias podiam embolsar como lucros ou repassar a seus fregueses, sob a forma de preços de venda mais baixos, e/ou a seus fornecedores, sob a forma de preços de compra mais altos. (...) 
Mais especificamente, como disse o próprio Steensgaard numa exposição sucinta de sua tese,

(tal como) o império do rei português, as companhias eram empresas integradas e não especializadas, mas com uma diferença marcante. Eram dirigidas como empresas e não como impérios. Ao produzirem sua própria proteção, as companhias não apenas expropriavam os tributos, como também ficavam aptas a determinar, elas mesmas, a qualidade e o custo da proteção. Isso significa que os custos de proteção foram introduzidos no leque de questōes ligadas aos cálculos racionais, em vez de permanecerem na imprevisível esfera dos "atos de Deus ou dos inimigos do Rei”. (Steensgaard, 1981, p. 259-260)

(...) Nessa comparação, a internalização dos custos de proteção aparece como o fenômeno que permitiu à classe capitalista holandesa levar os processos sistêmicos de acumulação de capital um passo à frente do que fizera a classe capitalista genovesa. (Arrighi, 1996, p. 148-149; grifos nossos)

Esta longa citação, antes de procurar transferir a análise para o campo da educação contemporânea, é uma forma de definir o que estamos entendendo por "internalização" e indicar a função deste processo. Trata-se de que um sistema ou subsistema incorpore alguns custos, controle melhor os processos e deixe de agregar outros desnecessários. A geração de excedentes pode ser apropriada ou usada como incentivo de consumo. Modernamente, o processo de internalização de custos completa-se com o seu oposto, a externalização de custos, um processo de ajuste tanto da flexibilização interna como da flexibilização externa.

Do ponto de vista econômico assiste-se a uma reorganização da firma que envolve sua reestruturação interna e externa. O primeiro nível se faz mediante a incorporação de novas máquinas, mudanças em estruturas hierárquicas, novos requerimentos de qualificação dos trabalhadores, novas técnicas organizacionais associados a uma estratégia de maior integração entre concepção e execução da produção e, ainda, estimulados por estratégias que permitam maior envolvimento dos trabalhadores e compromisso com os interesses específicos dos clientes e, portanto, da empresa.

O outro nível dessa mudança ocorre no seu relacionamento externo com as demais empresas, fornecedores, subcontratados, clientes, instituiçōes de pesquisa, universidades, governo etc., juntamente com a constituição de uma prática voltada para a inovação que fundamenta a busca permanente por vantagens competitivas. (Carleial, 2001, p. 11)

(...) a discussão da relação entre firmas será feita no contexto da Flexibilidade Externa da Firma considerada anteriormente (...). Entre os formatos da flexibilidade externa encontra-se a prática da subcontratação. (Carleial, 2001, p. 38)

Educ. Soc., Campinas, v. 23, n. 80, setembro/2002, p. 299-325 
Leia-se: terceirização. Por esta prática, o contratante fixa níveis de custos aos subcontratados e, conseqüentemente, protege seu lucro. Mais ainda, externaliza determinados custos agora sob responsabilidade da contratada (por exemplo, o transporte do produto pronto, os acidentes de trabalho, treinamento etc.), ganhando maior controle sobre a geração de sua margem de lucro.

No caso da escola, não está em jogo o lucro ou a apropriação de excedentes, mas sim o custo, o volume de investimentos em educação. Sabe-se que o "Estado mínimo" é também uma proposta para reduzir a pressão tributária sobre os negócios, permitindo maiores margens de lucro e competitividade às corporaçôes privadas.

Em um primeiro passo, a exclusão é internalizada (no sentido de que o aluno permanece na instituição escolar mesmo sem aprendizagem, ao contrário de quando era puramente eliminado da escola) e ganha-se clareza e controle sobre os seus custos econômicos (com Programas de Correção de Fluxo, Classes de Aceleração, Classes de Reforço etc.). Em um segundo momento, o custo pode ser externalizado, via privatização, por terceirização. Antes, os custos da repetência e da evasão eram informais, como um mal necessário, e faziam parte do próprio metabolismo de maneira não-racional (por exemplo, a defasagem idade/série), agora eles foram contabilizados e formalizados, sendo, portanto, passíveis de maior controle (correção de fluxo e equivalência idade/série).

A repetência e a evasão geram custos que oneram o Estado indevidamente - não são uma questão só de qualidade da escola. É uma questão de fluxo e de custo do fluxo. A questão da qualidade entra como geradora de menores gastos, menores custos - coerente, portanto, com a teoria do Estado mínimo. Custos desnecessários acarretam pressões por mais investimentos. O que está em jogo, portanto, não é apenas o lado humano e formativo da eliminação da reprovação ou da evasão, mas seu lado econômico, sistêmico - ou como se costuma dizer: o custo/benefício. A atenção está voltada para o ensino de disciplinas (em especial português e matemática) e não para a formação. Esta é a visão de qualidade que informa as políticas públicas neoliberais que se valem de sistemas nacionais de "avaliação" (SAEB, ENEM, ENC-Provão, SARESP etc.) para monitorar os resultados das escolas de forma quantitativa e genérica (comparativa), criar competição (segundo elas a mola mestra da qualidade) e reduzir gastos - o modelo é amplamente conhecido e aplicado no campo empresarial. ${ }^{6}$ Não é que esteja errada a preocupação com os gastos, 
é que em educação esta visão não é suficiente - não pode ser ponto de chegada. Esta visão economicista da qualidade faz com que jamais seja colocada para as políticas públicas neoliberais, por exemplo, a questão da escola em tempo integral - ela prefere criar penduricalhos ao redor da sala de aula (programas remediais e compensatórios) que são de menor custo; ou ainda, que não seja colocada a questão das finalidades formativas da educação.

É possível que a ênfase no ajuste do fluxo (Programas de Correção de Fluxo, Ciclos de Progressão Continuada, Recuperação de Ciclos, entre outras medidas em voga) vise a fazer uma ampla "faxina" do sistema de ensino de forma a corrigir seus custos econômicos e preparar processos de privatização por intermédio de terceirização, permitindo, por um lado, a internalização da exclusão de forma mais dissimulada quanto aos custos políticos e sociais e, por outro, a externalização dos custos econômicos, com aumento do controle sobre o processo educativo. A versão mais próxima disso é a transferência da operação de sistemas de ensino para empresas de educação terceirizadas, em que as contratantes ficam responsáveis pelos índices de aprovação e conseqüentemente internalizam para si os custos de reprovação e evasão. Os custos são, portanto, transferidos para as terceirizadas - não antes de torná-los suportáveis a partir de uma ampla intervenção na forma de funcionamento da escola, de maneira a ajustá-los previamente. Aqui, também, os custos da reprovação e evasão "foram introduzidos no leque de questôes ligadas aos cálculos racionais”, em vez de permanecerem na imprevisível esfera dos "atos de Deus ou dos inimigos do Rei”, conforme citação anterior de Arrighi. O que estaria em curso, portanto, é um processo de preparação de um modelo de privatização para o ensino no Brasil.

Mas, rapidamente se questionará esta análise dizendo ser ela uma defesa inaceitável da reprovação e da exclusão. Dirão que não podemos conviver com o desperdício de recursos, que a reprovação e a evasão revelam descaso com os investimentos públicos, com os alunos, com a sociedade etc. etc. Tudo isso tem um lado verdadeiro. Por isso, este conceito de internalização/externalização, embora elucidativo no plano econômico, não dá conta de todo o movimento. É preciso introduzir o conceito de "exclusão branda" de Bourdieu e Champagne (2001) para que se tenha uma visão de conjunto e se possa desvelar as intençôes que o discurso da racionalidade econômica encobre: 
Seria necessário mostrar aqui, evitando encorajar a ilusão finalista (ou, em termos mais precisos, o "funcionalismo do pior") como, no estado completamente diferente do sistema escolar que foi instaurado com a chegada de novas clientelas, a estrutura da distribuição diferencial dos benefícios escolares e dos benefícios sociais correlativos foi mantida, no essencial, mediante uma translação global de distâncias. Todavia, com uma diferença fundamental: o processo de eliminação foi diferido e estendido no tempo, e por conseguinte, como que diluído na duração, a instituição é habitada, permanentemente, por excluidos potenciais que introduzem nela as contradições e os conflitos associados a uma escolaridade cujo único objetivo é ela mesma. (Bourdieu, 2001, p. 221; grifos meus)

A diversificação dos ramos de ensino, associada a procedimentos de orientação e seleção cada vez mais precoces, tende a instaurar práticas de exclusão brandas, ou melhor, insensiveis, no duplo sentido de contínuas, graduais e imperceptíveis, tanto por aqueles que as exercem como por aqueles que são suas vítimas. A eliminação branda é para a eliminação brutal o que a troca de dons e contradons é para o "dá-se a quem dá": desdobrando o processo no tempo, ela oferece àqueles que têm tal vivência a possibilidade de dissimular a si mesmos a verdade ou, pelo menos, de se entregar, com chances de sucesso, ao trabalho de má-fé pelo qual é possível chegar a mentir a si mesmo sobre o que se faz. Em certo sentido, as "escolhas" mais decisivas são cada vez mais precoces (...) e o destino escolar é selado cada vez mais cedo (...) mas, em outro sentido, as conseqüências advindas dessas escolhas aparecem cada vez mais tarde, como se tudo conspirasse para encorajar e sustentar os alunos ou estudantes, em sursis, no trabalho que devem fazer para adiar o balanço final, a hora da verdade, em que o tempo passado na instituição escolar será considerado por eles como um tempo morto, um tempo perdido. (...)

Eis aí um dos mecanismos que, acrescentando-se à lógica da transmissão do capital cultural, fazem com que as mais altas instituições escolares e, em particular, aquelas que conduzem às posições de poder econômico e político, continuem sendo exclusivas como foram no passado. E fazem com que o sistema de ensino, amplamente aberto a todos e, no entanto, estritamente reservado a alguns, consiga a façanha de reunir as aparências da "democratização" (...). (Bourdieu, 2001, p. 223; grifos meus)

O conceito de "exclusão branda" assemelha-se ao conceito de "eliminação adiada” proposto por nós em 1991 (Freitas, 1991), com base em Bourdieu e Passeron (1975), quando procurávamos delimitar a extensão do campo da avaliação. Dizíamos:

Dessa forma, vemos, por fim, delimitar-se o campo da avaliação - entendida agora como estudo sistemático dos mecanismos de eliminação/manutenção. O campo da avaliação revela-se, transmuta-se no da hierarquia escolar. Mostra-se como produtor/legitimador desta hierarquia através da: 1 . 
manutenção propriamente dita das classes dominantes em profissões nobres; 2. eliminação adiada, ou manutenção provisória das classes populares em profissões menos nobres; 3 . manutenção adiada, ou exclusão pura e simples das camadas populares do interior da escola, ou seja, a evasão; 4. eliminação propriamente dita (privação), no sentido de impedir o ingresso das camadas populares na escola. Esta é a hierarquia escolar que os procedimentos convencionais de avaliação ocultam. (Freitas, 1991, p. 275)

A mudança no "metabolismo escolar" dá-se a partir de uma mudança na forma de exclusão, passando a insistir menos na modalidade 4 - eliminação por falta de vagas - (cujo custo econômico, social e político é maior inclusive pela pressão por maior escolarização, seja por necessidades do capital ou por exigência das próprias camadas populares) e a insistir mais nas modalidades 2 manutenção em profissões menos nobres - e 3 - evasão. Entretanto, mesmo assim, haveria aqui uma mudança na forma de construir a evasão, concentrando essa evasão entre ciclos (para não figurar nas estatísticas como evasão em séries) ou postergando-a para níveis mais elevados da escala de escolaridade (quando é considerada um fato mais "normal", dada a forma piramidal do acesso à educação em nossa sociedade). ${ }^{8}$

Esta forma de operar faz com que a exclusão se faça, de fato, segundo a bagagem cultural do aluno, o que permite que ela ocorra no próprio interior da escola de forma mais sutil, ou seja, "internalizada" (inclusive com menores custos políticos, sociais e com eventual externalização dos custos econômicos), e permite dissimular a exclusão social já construída fora da escola e que agora é legitimada a partir da ideologia do esforço pessoal no interior da escola, responsabilizando o aluno pelos seus próprios fracassos. Dessa forma, são criadas "trilhas de progressão continuada diferenciadas" na dependência do capital cultural de cada um e dos horizontes que estas criam para os próprios alunos, num processo de exclusão subjetiva, a partir dos horizontes de classe (Bourdieu e Passeron, 1975) ou a partir das condiçóes objetivas fornecidas nas próprias trilhas ou nos tipos de escolas e que são dissimuladas na forma de falta de aproveitamento pelo aluno das oportunidades concedidas.

Em resumo, os atos de exclusão do sistema têm custos (permanência por mais tempo no sistema, defasagem idade/série, evasão, repetência etc.) e estes são de várias ordens, todas interligadas entre si: sociais (dificuldades para consumir por falta de "cultura" mínima, aumento da disponibilidade [ao ficar fora da escola] para a violência, 
tráfico de droga, desnutrição, desordens sociais que perturbam o processo de acumulação e que impedem a "higienização" da força de trabalho), ${ }^{9}$ políticas (não-incorporação de hábitos e práticas esperadas pelo sistema do ponto de vista ideológico, de aceitação de padrões de vida etc.) e econômicos (custo do sistema e pressão sobre os investimentos em educação, tornando o Estado mais caro e portanto mais voraz em relação à arrecadação de tributos que competem com a apuração dos lucros das corporações, sem falar da pressão dos problemas sociais sobre os investimentos para conter a violência, epidemias, por exemplo etc.).

As políticas públicas criam um processo de dissimulação desses atos de exclusão do sistema (repetência, evasão), os quais, do ponto de vista político e social, são convertidos em atos do próprio sujeito (aluno), em um processo de auto-exclusão a partir das opções que faz, a partir do capital cultural anteriormente reunido em sua convivência na classe social respectiva, a partir das expectativas de classe e do seu esforço pessoal dentro do sistema escolar. Do ponto de vista econômico, criam um movimento duplo de internalização/ externalização em que no mínimo se ganha melhor controle sobre os custos e no máximo os terceirizam.

O sistema capitalista prevê que, ao precarizar as condições de trabalho cada vez mais, ao intensificar o processo de exploração (relativa e absoluta), ele vai gerar tensões sociais que precisam ser monitoradas e amenizadas para não comprometer o próprio processo de acumulação de capital. A educação tem um lugar entre as condições facilitadoras da reprodução do capital e um papel a cumprir.

A partir desta análise propomos nossa primeira tese:

TESE 1: QUANTO MAIS SE FALOU EM INCLUSÃO MAIS SE LEGITIMOU A EXCLUSÃO SOCIAL PRÉVIA À ESCOLARIZAÇĀO, POR UM MECANISMO DISSIMULATÓRIO DE INCLUSÃO FORMAL NA ESCOLA QUE TRANSMUTOU A EXCLUSÃO ESCOLAR OBJETIVA (REPETÊNCIA, EVASÃO) EM EXCLUSÃO ESCOLAR SUBJETIVA (AUTO-EXCLUSÃO ENTRE CICLOS, “OPÇŌES” POR TRILHAS DE PROGRESSÃO MENOS PRIVILEGIADAS, TRÂNSITO FORMAL SEM DOMÍNIO REAL), A PARTIR DOS HORIZONTES E DAS POSSIBILIDADES DE CLASSE PREVIAMENTE INTERIORIZADOS PELAS CONDIÇÕES OBJETIVAS DE CADA CLASSE NA SOCIEDADE.

Portanto, não se trata, aqui, de ser a favor da repetência, da reprovação ou evasão. Trata-se de mostrar que este processo apenas 
mudou sua forma de operar, a partir de sua internalização, motivada pela inclusão formal de $95 \%$ das crianças na escola. Tal processo de inclusão dá-se como resposta às próprias lutas das classes populares que exigem mais escolarização e por necessidades intrínsecas ao próprio processo de reestruturação produtiva que visa a estabelecer um novo padrão de exploração para a classe trabalhadora, incluída aí a necessidade de submeter um contingente cada vez maior de jovens às regras dominantes em uma escola cada vez mais controlada em seu conteúdo e método. O Estado procura atuar criando políticas públicas que viabilizem estas pressões.

Mas, como atuam, então, os procedimentos escolares responsáveis pela exclusão no interior?

$\mathrm{Na}$ realidade, os procedimentos são modulados pela função social que a escola assume no âmbito da sociedade. Em nossa sociedade a escola atua, entre outros aspectos, como mediadora entre hierarquias econômicas e hierarquias escolares e vice-versa (Bourdieu e Passeron, 1975; Bourdieu, 2001). A partir desta grande determinação, as demais ações internas configuram-se, cruzando-se com as correlaçôes de força locais que definem sua intensidade e, se necessário, obrigam a ações de controle mais eficazes por parte do Estado (outra não é a finalidade de avaliação externa). A escola, entretanto, não é apenas uma conseqüência, ela toma parte desta relação e tem uma função na constituição da sociedade - função que se pretende disputar e reorientar como parte de uma luta mais ampla e que está muito além da introdução de simples melhorias pedagógicas ou da absorção das classes populares em seu interior -, um fenômeno que se iniciou muito antes dos governos neoliberais mas que foi acelerado por estes com finalidade de ampliar o controle político-ideológico. Não há que esquecermos que a própria forma escolar ensina um certo sentido de “ordem", uma certa "posição nas relações de poder", independentemente da aprendizagem do seu conteúdo em si (disciplinas). A ênfase na necessidade de que todos acessem a escola, no momento em que o Estado amplia seu controle sobre o aparato escolar, não é inocente (ver também Enguita, 1989). É interessante notar que:

A situação atual pode parecer paradoxal. A forma escolar, o modo escolar de socialização domina a socialização, mas a escola como instituição é contestada, seu monopólio pedagógico e o dos docentes são retalhados, ameaçados... Entretanto, tal monopólio está ameaçado em nome da eficácia pedagógica, isto é, em nome dos resultados escolares, assim como em nome 
da "integração" das crianças e das famílias "populares" às normas dominantes, enquanto os métodos e o funcionamento da escola são contestados e atacados pelos sujeitos sociais mais escolarizados. (...) A preocupação em remediar o que se designa como fracassos da escola leva quase sempre a reproduzir as práticas escolares e prolongar a escolarização, com é demonstrado pela multiplicação das açôes de apoio escolar na periferia da escola ou pelas açōes de luta contra o "iletrismo" (...). (Vincent, Lahire e Thin, 2001, p. 46-47; grifos meus)

Inclusão é um tema recorrente em tempos neoliberais, contrastando com a crescente ampliação da exclusão social decorrente dessas próprias políticas, observável a olho nu na sociedade contemporânea. Esta aparente contradição revela a intenção de não se discutir "em que" ou "para que" se inclui. Ou, como nos lembra Almeida (2002), “(..) a opção por construir a possibilidade de inclusão significa aceitar e manter a sociedade que produz a exclusão, ou seja, busca-se constituir mecanismos que possibilitem aos sujeitos integrarem o tipo de sociedade que está posto" (p. 63) acriticamente. ${ }^{10}$

Mas deixemos este terreno mais abstrato e adentremos o campo das micro-práticas no interior da escola, em especial aquelas que estão ligadas à questão da avaliação. A escolha dessa categoria se faz pelo fato de ela ocupar um lugar central na prática pedagógica, tal como expusemos em Freitas (1995). Não é sem sentido que ela ocupe, também, lugar central nas políticas públicas atuais a partir da definição do Estado como um Estado avaliador. ${ }^{11}$

Um conjunto de estudos permitiu-nos construir tentativamente um modelo interpretativo para as práticas avaliativas (Freitas, 1991; Sobierajski, 1992; Villas Boas, 1993; Sordi, 1993; Pinto, 1994; Freitas, 1995; Camargo, 1996; Escobar, 1997; Godoy, 1997; Bertagna, 1997; Malavazi, 2000; Godoy, 2000).

Nesse modelo, a avaliação é vista apoiada em três práticas diferenciadas e ao mesmo tempo articuladas: avaliação instrucional, avaliação comportamental, avaliação de atitudes e valores. ${ }^{12}$ Com isso, retira-se a primazia da avaliação instrucional e combina-se esta dimensão com outras duas que têm um peso tanto ou mais decisivo na formação da auto-estima, no destino escolar do aluno e na sua conformação à "ordem”. As definiçôes usuais de avaliação, em geral, restringem-se a esta primeira dimensão - a função de verificar a aprendizagem do conteúdo escolar. Entretanto, a avaliação não está referida apenas à aprendizagem do conteúdo das disciplinas, mas é um potente instrumento de controle de sala de aula, tanto no que 
diz respeito ao comportamento (disciplina e motivação) como no que diz respeito à conformação de valores e atitudes.

A explicação para esta relação tripartite advém do fato de a escola ter sido institucionalizada de uma forma que, para acelerar os processos de formação, separou-se dos motivadores naturais da vida, ou da relação artesanal entre mestre e aprendiz. Puxada pelas necessidades vertiginosas da acumulação do capital, a escola foi obrigada a formalizar-se, separando-se da vida e subordinando tanto alunos como professores a "regras externas" a estes atores (sobre este último ponto cf. Vincent, Lahire e Thin, 2001, p. 15).

Os processos de avaliação, então, tomam o lugar desses motivadores naturais e passam a ser a principal ancoragem para produzir a motivação para o estudo - além da pressão familiar. Como na escola se aprendem/se ensinam relaçôes, a avaliação assume a forma de uma mercadoria com as características de dualidade existentes nesta na sociedade capitalista: valor de uso e valor de troca, com predomínio do último sobre o primeiro.

O aluno é cada vez mais conformado a ver a aprendizagem como algo que só tem valor a partir da nota (ou aprovação social), que lhe é externa, e a troca pela nota assume o lugar da importância do próprio conhecimento como construção pessoal e poder de interferência no mundo. $\mathrm{O}$ processo de avaliação adquire centralidade na escola porque faz parte da gênese do aparecimento da forma escolar - separada da vida (ainda que não do mercado).

Porém, é preciso complementar nosso entendimento do processo de avaliação escolar adicionando que este tripé avaliativo (instrucional, comportamental e de valores) atua em dois níveis: um formal e outro informal.

No plano formal estão a nota, o conceito ou a aprovação social verbal, como resultado do processo de ensino. No plano informal estão os juízos de valor que se configuram durante o processo de ensino/ aprendizagem - e não estamos falando aqui da avaliação formativa destinada a reorientar a aprendizagem. Estamos falando de juízos de valores dos atores - professores e alunos - que são desenvolvidos no processo de ensino/aprendizagem e que afetam as próprias estratégias de ensino/aprendizagem em nível encoberto - tanto estratégias do professor como dos alunos.

Professores e alunos defrontam-se na sala de aula construindo representaçōes uns dos outros. Tais representações e juízos orientam 
novas percepções, traçam possibilidades, estimam desenlaces, abrem ou fecham portas e, do lado do professor, afetam o próprio envolvimento deste com os alunos, terminando por interferir positiva ou negativamente com as próprias estratégias de ensino postas em marcha na sala de aula. É aqui que se joga o sucesso ou o fracasso do aluno - nesse plano informal e não no plano formal. De fato, quando o aluno é reprovado pela nota, no plano formal, ele já tinha sido, antes, reprovado no plano informal, no nível dos juízos de valor e das representações do professor - durante o próprio processo.

Como penetrar neste mundo pessoal do professor e do aluno? Certamente, não é por decretos e resoluções - nem pela avaliação externa. A questão que já se pode levantar é se a retirada da nota formal para permitir a progressão continuada do aluno afeta as ações do professor e do aluno no plano informal da sala de aula. A resposta pode ser encontrada nos graves problemas que a implantação dos ciclos de progressão continuada vem enfrentando. Sobre isso voltaremos mais adiante.

O diagrama abaixo resume - ainda que com alguma imprecisão - o modelo avaliativo que estamos aqui propondo.

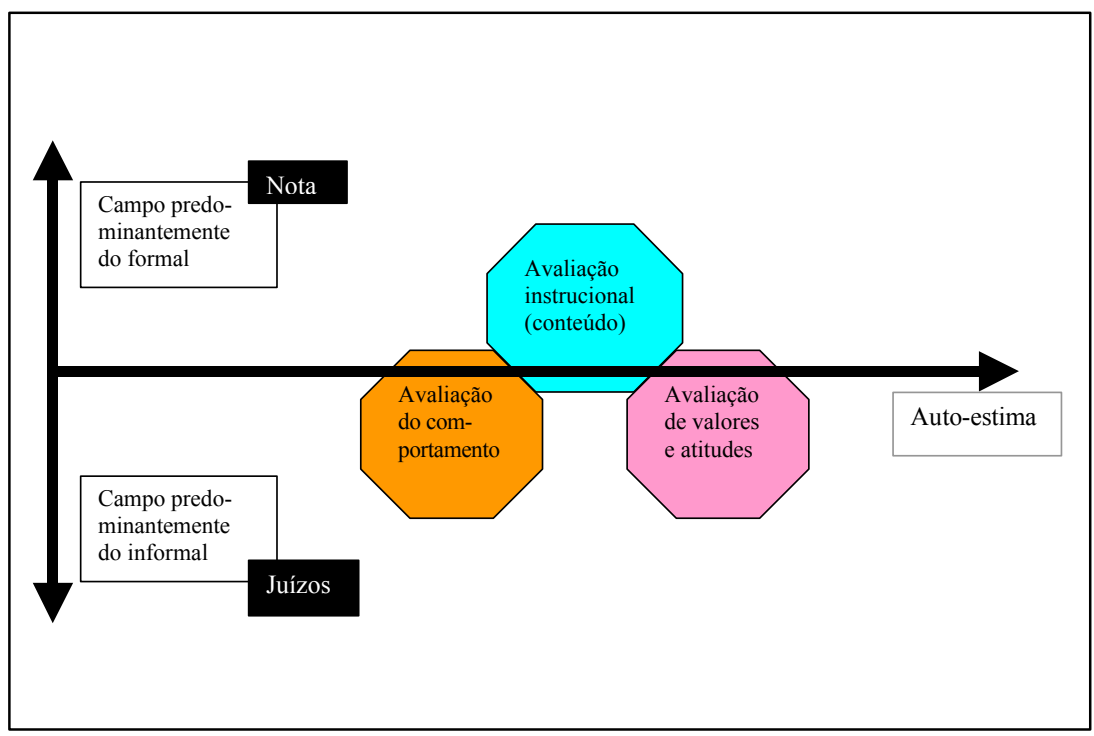

Esclarecida a natureza encoberta do processo de avaliação como fator que afeta as próprias estratégias de ensino (professor) 
e aprendizagem (aluno), podemos voltar para nossa análise e propor uma segunda tese.

TESE 2: QUANTO MAIS SE FALOU EM PROGRESSÃO CONTINUADA E EM NÃO REPROVAR FORMALMENTE PELA NOTA, MAIS SE REFORÇARAM OS PROCESSOS DE AVALIAÇÃO E REPROVAÇÃO INFORMAIS, QUE NO ÂMBITO DA FORMA ESCOLAR DETERMINAM OS PROCESSOS DE AVALIAÇÃO E REPROVAÇÃO FORMAIS, POR UM ARTIFÍCIO DE RECONVERSÃO DA REPROVAÇÃO FORMAL (NOTA) EM REPROVAÇÃO INFORMAL COM REGULAÇÃO DA AUTO-ESTIMA.

Esta tese explica a forma de operacionalização da tese anterior e mostra os mecanismos pelos quais se constrói a exclusão subjetiva, ou seja, pela relegação a determinadas trilhas desvalorizadas do ponto de vista escolar (classes de aceleração, reforço de ciclo, correção de fluxo etc.), as quais são correlatas de trilhas socialmente desvalorizadas (evasão entre ciclos, permanência em profissões menos nobres, cursos profissionalizantes etc.).

Examinando a reforma educacional portuguesa, Afonso Janela (2000) afirma:

Daí que, neste contexto, a consagração legal da avaliação formativa seja também uma decisão ambígua. Por um lado, trata-se de procurar diminuir a selectividade na educação básica, e assim tentar melhorar os índices de sucesso escolar considerados muito baixos para os padrōes europeus; por outro lado, espera-se que isso possa ser realizado através de um novo sistema de avaliação que, recusando a reprovação meramente administrativa, admita, todavia, a retenção pedagógica. (P. 82)

A internalização da exclusão permite um maior controle sobre os custos econômicos do sistema e sua eventual privatização e permite também produzir a seletividade - antes explícita e com custos sociais e políticos - na forma de exclusão subjetiva, a partir dos mecanismos de avaliação informal, nos quais se constrói de fato o sucesso ou o fracasso do aluno, mantendo de forma mais elegante as mesmas distâncias escolares relativas entre os alunos e a mesma vocação seletiva da escola. $\mathrm{O}$ sistema ganha com a permanência dos alunos na escola retirando-os do "mau convívio" da rua, disciplinando-os segundo a "ordem" vigente, inculcando a visão políticoideológica dominante, ainda que não ensine de fato mais do que ensinava antes - como acusam os professores que trabalham nos sistemas por ciclos de progressão continuada. 
Antes de continuarmos é importante entendermos a lógica da organização escolar por ciclos.

Os ciclos procuram contrariar a lógica da avaliação formal. Os ciclos não eliminam a avaliação (nem formal e muito menos a informal), mas redefinem seu papel e sua autoria e associam-na com ações complementares (por exemplo, recuperação paralela). A motivação para tal e as possibilidades efetivas de seu sucesso dependem das políticas públicas e das concepções de educação que estão na base dos ciclos, entre outros aspectos que fogem ao nosso objetivo aqui. A mudança da autoria da avaliação tem sido um dos problemas graves, pois o professor tende a perder controle sobre o resultado de seu trabalho produzindo efeitos motivacionais desastrosos sobre ele. ${ }^{13}$

Souza e Alavarse advertem que:

Embora se observe o emprego generalizado da expressão ciclos, na literatura, na legislação e em documentos de várias redes públicas de ensino do país, para caracterizar uma organização de ensino oposta à seriação, uma análise mais detalhada de seu emprego indica uma diversidade de conceitos, bem como de iniciativas de organização escolar. (2002, p. 7)

Basta compararmos as estratégias de ciclo utilizadas na Prefeitura Municipal de Belo Horizonte com as utilizadas na Secretaria de Educação do Estado de São Paulo para que se tenha um exemplo de tais diferenciações - seja nos conceitos, seja nas formas de aplicação e implantação.

Em São Paulo os ciclos são uma junção de séries convencionais (conjuntos de quatro anos $-1^{\mathrm{a}}$ à $4^{\mathrm{a}}$ série em um ciclo e $5^{\mathrm{a}}$ e $8^{\mathrm{a}}$ séries em outro), caracterizando muito mais ciclos de progressão continuada do que ciclos de formação. No ciclo de formação os espaços e tempos escolares são reordenados em função do desenvolvimento da criança (geralmente ciclos de três anos): infância, pré-adolescência e adolescência. Nestes a ênfase está na vivência de experiências significativas para as idades e para a vida. ${ }^{14}$

A tentativa realizada nos ciclos de progressão continuada, de retirar os efeitos da avaliação formal durante um determinado conjunto de anos, revela um desconhecimento de como ocorre o processo de avaliação no interior da escola, pois, como dissemos antes, o destino do aluno é jogado no interior da avaliação informal e não na avaliação formal. Entretanto, ao retardar os efeitos formais 
da nota, o sistema quebra o tripé avaliativo e desarma o professor que fica sem ter "motivadores" para lidar com o aluno em sala de aula durante longos períodos. Gera efeitos colaterais. A “ordem” na sala de aula convencional, certo ou errado, ancora-se na nota. Há que se lembrar que a gênese do sistema escolar substitui motivadores naturais por motivadores artificiais baseados no valor de troca do “conhecimento" (pela nota) junto ao professor. É este processo de troca que permite ao professor criar os motivadores artificiais que regulam as relações (inclusive disciplinares) em sala de aula. A questão é que este processo foi sustado sem que houvesse preparação do professor e sem que o aluno fosse desafiado por meio de outros motivadores para o estudo. Isso significa que o professor ficou totalmente dependente do processo de avaliação informal e, portanto, significa que ele está se dando de uma maneira muito mais forte. É um equívoco pensar exclusivamente em termos de avaliação formal, pois isso nos leva a uma discussão estéril sobre se somos ou não a favor da nota como forma de controle em sala de aula. A nota como motivador artificial não é uma invenção do professor, mas uma necessidade da escola como um sistema artificial que tem uma função social excludente, a mando do sistema que a cerca. Que isso ocorra mais ou menos dissimuladamente não altera sua vocação, mas é um importante elemento ao se pensar a sua superação.

Do ponto de vista do professor, os ciclos aparecem como uma retirada de seu poder e uma retirada do controle sobre o processo de trabalho. Dessa forma, prolifera a idéia de que ele já não tem que se preocupar com os resultados da aprendizagem dos alunos, pois o que o sistema quer é que ele "empurre o aluno para a frente a qualquer custo”. Dessa maneira, ocorre uma desresponsabilização pelo processo de ensino. ${ }^{15}$

Isso nos leva a nossa terceira e última tese.

TESE 3: QUANTO MAIS SE FALOU EM RESPONSABILIZAR A ESCOLA PELO ENSINO PARA TODOS, MAIS SE DESRESPONSABILIZOU A AÇÃO DA ESCOLA PELA APRENDIZAGEM DAS CAMADAS POPULARES.

Os mecanismos de transferência de responsabilidade do Estado para o indivíduo são bastante conhecidos no âmbito das políticas públicas neoliberais. Na questão do emprego isso é notório. Emprego é substituído por empregabilidade - ou seja, a capacidade que o INDIVÍDUO acumula de obter emprego a qualquer momento. A 
desresponsabilização vem na esteira da minimização do Estado, que transfere responsabilidades para os indivíduos ou para entidades nãogovernamentais. Dessa mesma forma, a escola como local de preparação de relaçôes sociais, deve ensinar os alunos a serem donos de sua própria aprendizagem - cabendo a ela apenas propiciar oportunidades de aprendizagem e de reforço para o aluno em caso de necessidade -, uma espécie de "teoria da focalização" na escola. O aluno deve responsabilizar-se pela sua aprendizagem. Caso não o faça, será reprovado pela vida e a culpa será apenas dele. A desresponsabilização do professor faz parte de uma redefinição de seu papel no processo de aprendizagem, com base em um modelo individualista de desenvolvimento pessoal: a cada um segundo o seu esforço. Deve-se "aprender a aprender".

Entretanto, esta forma de analisar o papel do aluno esquece as formas de "acumulação primitiva" do capital cultural. Marx (1983) examina detalhadamente como se deu a acumulação primitiva do capital econômico e como, em seguida, este processo é esquecido e legitimado como se tivesse sido obtido pelos exploradores com seu próprio suor. Diz ele:

Essa acumulação primitiva desempenha na Economia Política um papel análogo ao pecado original da Teologia. (...) Em tempos muito remotos, havia, por um lado, uma elite laboriosa, inteligente e sobretudo parcimoniosa, e, por outro, vagabundos dissipando tudo o que tinham e mais ainda. (...) E desse pecado original data a pobreza da grande massa que até agora, apesar de todo seu trabalho, nada possui para vender senão a si mesma, e a riqueza dos poucos, que cresce continuamente, embora há muito tenham parado de trabalhar. (Marx, 1983, p. 261)

Guardadas as devidas proporções, assim também ocorre com o próprio capital cultural e social (Bourdieu, 2001) com o qual o aluno pisa na escola no primeiro dia. Os alunos não chegam à escola em condições de igualdade em relação às oportunidades que tiveram. "Lavado", esse capital inicial é legitimado como se tivesse sido obtido pelo esforço pessoal de cada um. A desresponsabilização do professor deixa cada aluno à mercê de seu próprio esforço, à mercê de sua própria "acumulação primitiva" - que para as camadas populares inexiste ou é pequena. As opções dentro do sistema escolar e as formas de sair de dentro dele são produzidas neste processo. Por isso que a metodologia do "aprender a aprender" ${ }^{16}$ é uma forma de legitimação, no interior da escola, das diferenças sociais previamente existentes. 
Não se deve concluir desta análise que a escola está irremediavelmente perdida. Os ciclos devem ser mecanismos de resistência à lógica seriada. Mas devem ser vistos como oportunidade para se elevar a conscientização e a atuação dos professores, alunos e pais, retirando-os do senso comum e revelando as reais travas para o desenvolvimento da escola e da sociedade - e não apenas serem vistos como uma "solução" técnico-pedagógica para a repetência.

A escola continua sendo um espaço de luta que, entretanto, não pode ser ocupado ingenuamente com o espírito de "fazer justiça com as próprias mãos" e promover eqüidade, sem levar em conta as relaçôes que se estabelecem entre a escola e a sociedade. Significa, ainda, que as modificações desejadas na escola devem estar ancoradas nos movimentos sociais que lutam pela emancipação do homem, e não nas necessidades que o sistema capitalista tem de adequar a escola à lógica da reestruturação produtiva. Nesse processo cumpre papel esclarecedor a concepção de sociedade e de educação que está por trás das propostas educacionais.

É preciso conhecer os limites da escola para poder explorar melhor suas possibilidades. Este foi o equívoco dos que descartaram Bourdieu como sendo um crítico-reprodutivista. Entretanto, neste texto, não é nosso propósito o exame de tais possibilidades. Apenas queremos deixar antever, por contraste, uma alternativa às políticas públicas neoliberais. $\mathrm{O}$ quadro que segue resume as características de uma política pública alternativa e que orienta uma forma diferente de ver a escola, os ciclos e a avaliação, e destina-se a construir uma verdadeira escola para todos - como possibilidade de acesso e como qualidade.

\begin{tabular}{|l|l|}
\hline \multicolumn{2}{|c|}{$\begin{array}{c}\text { DIMENSÕES CONTRADITÓRIAS DE CONCEPÇÕES } \\
\text { DE EDUCAÇÃO, CICLOS E AVALIAÇÃO }{ }^{17}\end{array}$} \\
\hline $\begin{array}{l}\text { Projeto histórico conservador de otimização da } \\
\text { escola atual, imediatista e que visa ao alinhamento da } \\
\text { escola às necessidades da reestruturação produtiva. }\end{array}$ & $\begin{array}{l}\text { Projeto histórico transformador das bases de } \\
\text { organização da escola e da sociedade, de médio e } \\
\text { longo prazos, que atua como resistência e fator de } \\
\text { conscientização, articulado aos movimentos } \\
\text { sociais. }\end{array}$ \\
\hline $\begin{array}{l}\text { Fragmentação curricular e metodológica que no } \\
\text { máximo prevê a articulação artificial de discipli- } \\
\text { nas e séries (ciclos de progressão continuada, } \\
\text { temas transversais, por exemplo). }\end{array}$ & $\begin{array}{l}\text { Unidade curricular e metodológica de estudos em } \\
\text { torno de aspectos da vida, respeitando as experi- } \\
\text { ências significativas para a idade (ciclos de forma- } \\
\text { ção, ensino por complexos, por exemplo). }\end{array}$ \\
\hline Conteúdo preferencialmente cognitivo-verbal. & $\begin{array}{l}\text { Desenvolvimento multilateral, baseado nas } \\
\text { experiências de vida e na prática social. }\end{array}$ \\
\hline
\end{tabular}

Educ. Soc., Campinas, v. 23, n. 80, setembro/2002, p. 299-325 


\begin{tabular}{|c|c|}
\hline $\begin{array}{l}\text { Aponta para a alienação, para o individualismo } \\
\text { do aluno e a subordinação do professor e do } \\
\text { aluno, aprofundando relaçôes de poder verticali- } \\
\text { zadas na escola (ênfase no papel do diretor e do } \\
\text { especialista). } \\
\text { Treinamento do professor; preparação do peda- } \\
\text { gogo como especialista separado do professor (e } \\
\text { vice-versa), com o fortalecimento da separação } \\
\text { entre o pensar e o fazer no processo educativo. } \\
\text { Uso de tecnologias para substituir o professor } \\
\text { e/ou acelerar os tempos de estudo. }\end{array}$ & $\begin{array}{l}\text { Favorece a auto-organização do aluno, o trabalho } \\
\text { coletivo e a cooperação no processo, criando } \\
\text { mecanismos de horizontalização do poder na } \\
\text { escola. } \\
\text { Formação do professor no educador. } \\
\text { Subordinação das tecnologias ao professor, com a } \\
\text { finalidade de aumentar o tempo destinado pela } \\
\text { escola à formação crítica do aluno. }\end{array}$ \\
\hline $\begin{array}{l}\text { Sistema excludente e/ou hierarquizador (exclusão } \\
\text { pela inclusão na escola). } \\
\text { Desresponsabilização da escola pelo ensino. } \\
\text { Terceirização/privatização. }\end{array}$ & $\begin{array}{l}\text { Educação como direito de todos e obrigação do } \\
\text { Estado. }\end{array}$ \\
\hline $\begin{array}{l}\text { Retirada da aprovação do âmbito profissional do } \\
\text { professor, mantendo inalterada a avaliação } \\
\text { informal com característica classificatória. }\end{array}$ & $\begin{array}{l}\text { Ênfase na avaliação informal com finalidade } \\
\text { formativa e ênfase no coletivo como condutor do } \\
\text { processo educativo. }\end{array}$ \\
\hline $\begin{array}{l}\text { "Avaliação" formal externa do aluno e do profes- } \\
\text { sor (de difícil utilizaçáo local) como controle. }\end{array}$ & $\begin{array}{l}\text { Avaliação compreensiva, coletiva e com utilização } \\
\text { local. }\end{array}$ \\
\hline $\begin{array}{l}\text { Avaliação referenciada em conteúdos instrutivos } \\
\text { de disciplinas, padronizados em habilidades e } \\
\text { competências. }\end{array}$ & $\begin{array}{l}\text { Avaliação referenciada na formação e no próprio } \\
\text { aluno, em face dos objetivos da educaçáo e em } \\
\text { face da vida (formação e instruçáo). }\end{array}$ \\
\hline
\end{tabular}

A luta por uma escola para todos somente poderá ser conseqüente quando a escola for, além de um local de aprendizagem, um local de tomada de consciência e de luta contra as desigualdades sociais em estreita relação com os movimentos sociais emancipatórios, quando então a escola encontrará seu lugar formativo/instrutivo no nosso tempo. Além de conteúdo, a escola deve ensinar novas relações com as pessoas e com a natureza. Mais do que nunca, temos que saber ler as medidas que estão sendo propostas usando um instrumental teórico que nos permita desvelar as reais intenções e as práticas das atuais políticas públicas e armar a resistência. O neoliberalismo e suas "teorias" educacionais passarão ${ }^{18}$ - ainda que nos reste muita luta.

\section{Recebido e aprovado em julho de 2002.}

\section{Notas}

1. É oportuno recordar a entrevista de John Kenneth Galbraith à Folha de S. Paulo: "Globalização não é um conceito sério. Nós, os americanos, o inventamos para dissimular a nossa política de entrada econômica nos outros países. Infelizmente, essa é uma mensagem que chega com dificuldade em um país como o Brasil, sempre 
propenso a se encantar com os modismos internacionais mais vagabundos" (FSP, 9/ 4/1998, Caderno 2, p. 2).

2. Para uma visão destes padrōes de funcionamento, consultar Arrighi, 1996, e Arrighi e Silver, 2001.

3. Sobre isso alertei em 1992, em um trabalho chamado Neotecnicismo e formação do educador, em Alves (org.), Formação do educador: pensar e fazer, São Paulo: Cortez, 1992.

4. Projeto Internacional para a Produção de Indicadores de Rendimento dos Alunos (PISA), sob os auspícios da Organização para a Cooperação e o Desenvolvimento Econômico (OCDE).

5. Tais sistemas são de fato levantamentos de informação e verificação de rendimento não podendo ser considerados sistemas de avaliação, já que não possuem formas de retorno adequadas aos avaliados que permitam encaminhar a superação da situação avaliada. Sobre esta questão ver Freitas et al. (2002a).

6. Os recentes escândalos que atingem grandes corporações nos Estados Unidos, acusadas de fraudar seus balanços para manterem posiçōes confortáveis nas Bolsas de Valores, mostram-nos a real face do "mercado", o tão infalível e regulador mercado...

7. Ver também Bourdieu (coord.), A miséria do mundo, Rio de Janeiro: Vozes, 2001, 4. ed., p. 481 .

8. No site da Secretaria de Educação do Estado do Paraná pode-se ler um balanço dos resultados do Programa de Correção de Fluxo que diz: "A efetividade do Projeto acaba por provocar uma forte alteração nos indicadores de produtividade da rede estadual de ensino, reduzindo quase à metade a reprovação de $5^{\mathrm{a}}$ à $8^{\mathrm{a}}$ série, entre 1996 e 1999 (de $17,2 \%$ para $10,5 \%)$. Houve também uma diminuição em cerca de um terço nas taxas de abandono das séries finais do ensino fundamental (de 12,8\% para 8,1\%) no mesmo período”. Os números nada dizem, entretanto, sobre a destinação escolar e social dos alunos. Sabe-se por exemplo que alunos que no interior do Paraná têm em seu histórico escolar registrado terem feito o Programa de Correção de Fluxo têm dificuldades para serem aceitos em determinadas empresas (Rippel, 2002).

9. No site da Secretaria de Educação do Estado do Paraná pode se tomar ciência de um Projeto com este objetivo: "As precárias condições de vida familiar fazem com que as crianças e adolescentes procurem formas alternativas de sobrevivência, comprometendo sua integridade e desenvolvimento físico, intelectual, social e emocional, ficando excluídos do convívio familiar, do acesso à escola e, conseqüentemente, de exercer sua efetiva cidadania. O Governo do Estado, preocupado com esta realidade social, está implantando em todo o Paraná, o Projeto Da Rua Para a Escola, que é uma ação articulada entre a Secretaria de Estado da Criança e Assuntos da Família e a Secretaria de Estado da Educação". E ainda: "Trata-se de repasse mensal de uma cesta básica de alimentos às famílias integradas ao projeto, que têm, como compromisso, assegurar às suas crianças e adolescentes, o ingresso, o regresso e a permanência na escola e no convívio familiar".

10. Ver também Ribeiro, 1999.

11. Sobre a questão das políticas públicas e da avaliação pode-se consultar Afonso Janela, 2000.

12. Em Freitas (1995) estas dimensōes são explicadas e exemplificadas com base em estudos da prática pedagógica de escolas.

13. No caso do estado de São Paulo a autoria da avaliação está sendo transferida para uma agência externa à escola, por intermédio do SARESP.

14. Sobre a experiência da Prefeitura Municipal de Belo Horizonte pode-se consultar os trabalhos de Dalben (coord.), Avaliação da implementação do Projeto Político-Pedagógico

Educ. Soc., Campinas, v. 23, n. 80, setembro/2002, p. 299-325

Disponível em <http://www.cedes.unicamp.br> 
Escola Plural, Game, fae, UfmG, 2000a, e Dalben, (org.), Singular ou Plural? Eis a escola em questão! GAME, FAE, UFMG, $2000 \mathrm{~b}$.

15. Esta constatação, na verdade, é a mesma formulada por Saviani em relação à Escola Nova, em Escola e democracia, São Paulo: Cortez, 1983.

16. Para uma abordagem crítica do "aprender a aprender" ver também Duarte, 2000.

17. Uma versão preliminar deste quadro foi publicada em Freitas, Ciclos de progressão continuada: vermelho para as políticas públicas, Revista Eccos, jun. 2002.

18. Sobre o provável destino da hegemonia norte-americana ver o artigo de Immanuel Wallerstein na Folha de S. Paulo, 21/7/2002, Caderno B, p. 6-7. Entretanto, há que se ter presente que a queda da hegemonia norte-americana não representa necessariamente o fim do capitalismo. Ver, também, as obras de Arrighi que citamos ao final.

\section{Referências bibliográficas}

ALMEIDA, M.I. Ações organizacionais e pedagógicas dos sistemas de ensino: políticas de inclusão? In: RosA, D.E.G.; SouZA, V.C. (Orgs.). Politicas organizativas e curriculares, educação inclusiva e formação de professores. Rio de Janeiro: DP\&A; Goiânia: Alternativa, 2002.

AFONSO, A.J. Avaliação educacional: regulação e emancipação. São Paulo: Cortez, 2000.

ARRIGHI, G. O longo século XX. Rio de Janeiro: Contraponto; São Paulo: Ed. da UNESP, 1996.

ARRIGHI, G.; SILVER, B. Caos e governabilidade no moderno sistema mundial. Rio de Janeiro: Contraponto/UeRJ, 2001.

BERTAGNA, R.H. Avaliação da aprendizagem escolar: a visão de alunos de $4^{\mathrm{a}}$ e $5^{\mathrm{a}}$ séries do $1^{\circ}$ grau. 1997. 192f. Dissertação (Mestrado em Educação) - Faculdade de Educação, Universidade Estadual de Campinas, Campinas.

BOURDIEU, P. Escritos de educação. 3. ed. Petrópolis: Vozes, 2001.

BOURDIEU, P. A miséria do mundo. 4. ed. Petropólis: Vozes, 2001.

BOURDIEU, P.; CHAMPAGNE, P. Os excluídos do interior. In: Bourdieu, P. Escritos de educação. 3. ed. Petrópolis: Vozes, 2001.

BOURDIEU, P.; PASSERON, J.C. A reprodução: elementos para uma teoria dos sistemas de ensino. Rio de Janeiro: F. Alves, 1975. 
CAMARGO, A L.C. O discurso sobre a avaliação escolar do ponto de vista do aluno. 1996. 343f. Tese (Doutorado em Educação) - Faculdade de Educação, Universidade Estadual de Campinas, Campinas.

CARLEIAL, L. Redes industriais de subcontratação. São Paulo: Hucitec, 2001.

DALBEN, A.I.L.F. (Coord.). Avaliação da implementação do Projeto Politico-Pedagógico Escola Plural. [Belo Horizonte]: GAME/FAE/ UFMG, 2000a.

DALBEN, A.I.L.F. (Org.). Singular ou plural?: eis a escola em questão! [Belo Horizonte]: GAME/FAE/UFMG, $2000 \mathrm{~b}$.

DUARTE, N. Vigotski e o "aprender a aprender": crítica às apropriações neoliberais e pós-modernas da teoria vigotskiana. Campinas: Autores Associados, 2000.

ENGUITA, M.F. A face oculta da escola: educação e trabalho no capitalismo. Porto Alegre: Artes Médicas, 1989.

ESCOBAR, M.O. Transformação da didática: construção da teoria pedagógica como categorias da prática pedagógica: experiência na disciplina escolar educação física. 1997. 195f. Tese (Doutorado em Educação) - Faculdade de Educação, Universidade Estadual de Campinas, Campinas.

FRANCO, C. (Org.) Avaliação, ciclos e promoção na educação. Porto Alegre: Artes Médicas, 2001.

FREITAS, L.C. A dialética da eliminação no processo seletivo. Educ. Soc., Campinas, v. 12, n. 39, p. 265-285, 1991.

FREITAS, L.C. Neotecnicismo e formação do educador. In: Alves, N. (Org.). Formação do educador: pensar e fazer. São Paulo: Cortez, 1992.

FREITAS, L.C. Critica da organização do trabalho pedagógico e da didática. Campinas: Papirus, 1995.

FREITAS, L.C. et al. Avaliação escolar e ensino público: formação continuada para professores do ensino básico. Programa FAPESP/ Ensino público. Relatório de pesquisa, 2000.

FREITAS, L.C. et al. Avaliação: construindo o campo e a crítica. Florianópolis: Insular, 2002a. 
FREITAS, L.C. Ciclos de progressão continuada: vermelho para as políticas públicas. Revista Eccos, São Paulo, v. 4, n. 1, jun. 2002.

GAlBRAITH, J.K. Entrevista. Folha de S. Paulo, São Paulo, 9 abr. 1998. Caderno 2, p. 2.

GODOI, E.G. Avaliação escolar no ciclo básico. 1997. Monografia (Graduação) - Faculdade de Educação, Universidade Estadual de Campinas, Campinas.

GODOI, E.G. Educação infantil: avaliação escolar antecipada? 2000. 186f. Dissertação (Mestrado em Educação) - Faculdade de Educação, Universidade Estadual de Campinas, Campinas.

GUIMARÃES, A. Ensino no Ceará fere a $L D B$ há dez anos: metodologia moderna, que usa transmissão de de aulas pela tv, provoca polêmica na educação cearense. Disponível em: <www.uol.com.br/ novaescola> Acesso em maio 2002.

MALAVAZI, M.M.S. A visão dos pais acerca da avaliação escolar. 2000. Tese (Doutorado em Educação) - Faculdade de Educação, Universidade Estadual de Campinas, Campinas.

MARX, K. O Capital: crítica da economia política. São Paulo: Abril Cultural, 1983. v. 1, t. 1.

PINTO, A.L.G. A avaliação da aprendizagem: o formal e o informal. 1994. 147f. Dissertação (Mestrado em Educação) - Faculdade de Educação, Universidade Estadual de Campinas, Campinas.

RIBEIRO, M. Exclusão: problematização do conceito. Educação e Pesquisa, São Paulo, v. 25, n. 1, p. 35-49, 1999.

RIPPEL, V.C.L. Os caminhos da educação - Projeto Correção de Fluxo: um estudo de caso em Toledo, Paraná. 2002. Dissertação (Mestrado em Educação) - Faculdade de Educação, Pontifícia Universidade Católica de Campinas, Campinas.

SAVIANI, D. Escola e democracia. São Paulo: Cortez, 1983.

SOBIERAJSKI, M.S. Explorando a prática da avaliação em uma $5^{a}$ série do $1^{\circ}$ grau. 1992. 187f. Dissertação (Mestrado em Educação) Faculdade de Educação, Universidade Estadual de Campinas, Campinas. 
SORDI, M.R.L. Repensando a prática e avaliação no ensino de enfermagem. 1993. 328f. Tese (Doutorado em Educação) Faculdade de Educação, Universidade Estadual de Campinas, Campinas.

SOUZA, P.R. Copo meio cheio ou copo meio vazio. Folha de S. Paulo, São Paulo, p. 3, 11 dez. 2001.

SOUZA, S.M.Z.L.; ALAVARSE, O.M. Ciclos: a centralidade da avaliação. Documento apresentado no 2. Seminário de Avaliação do LOED. Campinas: FE/UnicAmp, 2002.

VILLAS BOAS, B.M.F. As práticas avaliativas e a organização do trabalho pedagógico. 1993. 481f. Tese (Doutorado em Educação) - Faculdade de Educação, Universidade Estadual de Campinas, Campinas.

VINCENT, G.; LAHIRE, B.; THIN, D. Sobre a história e a teoria da forma escolar. Educação em Revista, Belo Horizonte, n. 33, p. 7-47, 2001.

WALLERSTEIN, I. O declínio do império americano. Folha de $S$. Paulo, São Paulo, 21 jul. 2002. Caderno B, p. 6-7. 